\title{
Non-surgical Collection of Uterine Eggs in the Rat
}

\author{
Yoshiro ISHIJIMA, Mamoru TOGASHI and Shogo KITAJIMA \\ Department of Zootechnical Science, Tokyo University \\ of Agriculture, Setagaya-ku, Tokyo 156, Japan
}

(Received for publication Feburary 29, 1980)

\begin{abstract}
The non-surgical collection of rat embryos were examined. The apparatus for uterine flushing (Fig. 1 and 2) were designed to have a two-way system. Egg collection were made 5 days after mating. Eggs were collected from anesthetized donors using a pair of glass pipettes inserted to the end of each uterine horn through the cervix uteri. By non-surgical technique, it was successful to collect the eggs at an average of 4.0 from all the animal. The recovery rate was $40.7 \%$ as estimated the number of corpora lutea counted after the slaughter of the donor. The recovery rate in non-surgical methods was considerably lower as compared with that of the uterine flushing after the slaughter.
\end{abstract}

\section{ラット子宮内卵子の非外科的採取}

石島芳郎・富樫守・北島省吾

東京農業大学畜産学科

ラット，マウス，八ムスターなどの実験動物の卵子の 採取は，一般には動物をそのつどと殺し，摘出した卵 管・子宮を灌流する方法が用いられているが，この方法 では同一個体の卵子を何度も使用することができないの で, 遺伝, 育種上の研究に卵子を利用する際に, 近交系 でない動物では不都合を生じる場合がある。従って，実 験動物においても，家畜で開発されているよらな生体の まま手術によって採卵する外科的方法や頸管経由で子宮 内の胚を採取する非外科的方法があれば便利である[1]。 しかしながら，実験動物では体が小さいこともあって， この種の試みはほとんど検討されておらず $[2,12]$ とく に非外科的採卵に関しては, ウサギで交尾後種々のホル モンを投与して，腔に落した卵子を採取した例 [7〜11] がある以外は見当らない。そこで本実験では, ラットの 子宮内胚の非外科的採取法の開発を目的に, 先ずごく簡 単な大小 2 本のガラス管を利用して採取を試みた。
この実験には本学で閉鎖集団として維持している Sprague-Dawley 系ラットの成熟未経産雌（生後 $3 \sim 4$ 力月齢）を供試した。飼育は室温 $23^{\circ} \mathrm{C} \pm 1^{\circ} \mathrm{C}$, 明暗 12 時間：12時間の条件下で行なった。

供試ラットは, 性周期の規則正しいものを選び, スメ 了検査によるI 期の夕方 5 時に雌雄 $1 ： 1$ の割合で同居 させ，翌朝スメア中に精子を確認したもののみを用い て, 交配後 5 日目の午前中に卵子の採取を行なった。

非外科的卵子の採取は Fig1 2 に示すような方法で 行なった。すなわち, 倠ラットをネンブタールで麻酔し て保定台にあ拈むけに保定し，最初にオートスコープを 腔に插入して子宮頸管外口部を見ながら誘導用ガラス棒 を頸管を通して子宮内に㨉入する（Fig 1-1）。次に才 ートスコープを抜き取り，ラッパ状ガラス管を誘導用ガ ラス棒に沿って子宮内に挿入する（Fig 1-2）。次いで 誘導用ガラス棒を抜き取り, 子宮灌流液注入用ピペット 

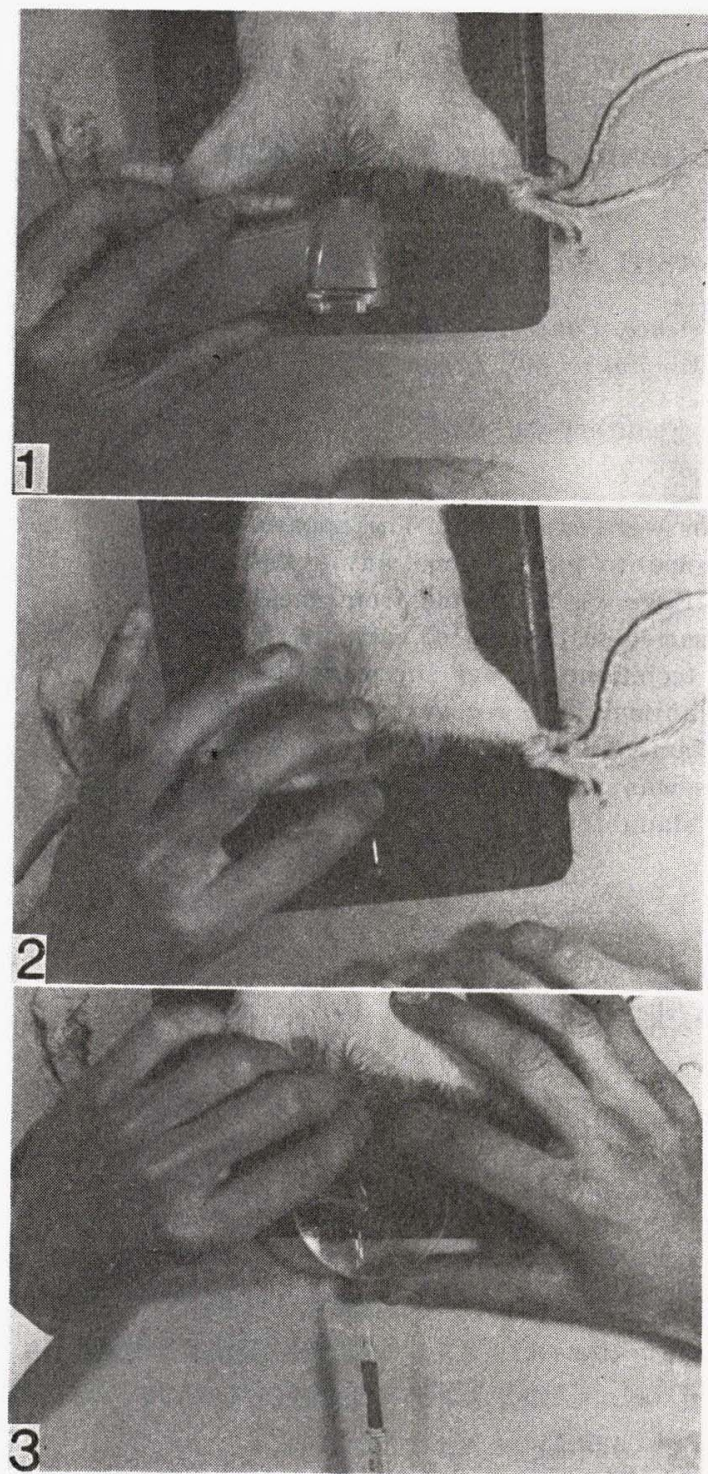

Fig. 1 The apparatus and procedure used in the present study for the non-surgical recovery of uterine embryos of rats. 1 . The narrow glass rod as inducer was inserted into the uterine lumen through the cervix using an otoscope. 2 . The trumpet-shaped glass tube was gently inserted into the end of uterine lumen through the cervix along the inducer, and then removed inducer. 3. The narrow glass pipette was passed into the uterine lumen turough the trumpet-shaped glass tube. Then, flushing fluid was infused through a glass pipette by an injector. The washings returned through the glass tube were recovered in the watch-glass.
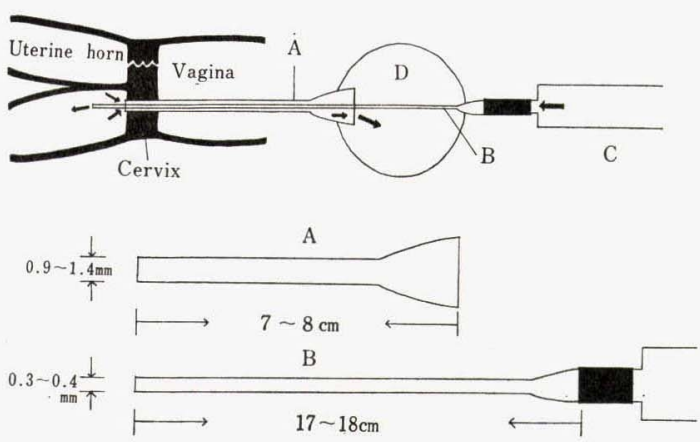

Fig. 2 Diagram of methods used for the nonsurgical flushing. A. Trumpet-shaped glass tube, B. Glass pipette, C. Syringe D. Watch-glass.

をラッパ状ガラス管の中を通して子宮内に届くように挿 入し，ゴム管でつないだ注射筒内の灌流液 $(0.85 \%$ 生理 的食塩水, 1 回に $0.6-1 \mathrm{ml}$ ) を静かに注入していく (Fig 1-3)。このよらな手順でラッパ状ガラス管を通っ てもどってくる液（液回収率70\%）を時計血に受け取っ た (Fig2)。この方法は両側の子宮角に行なった。採取 器具の形, 大ささはFig 2 に示す通りである。卵子を 採取後, 雌をと殺し黄体数を検査し, 黄体数を排卵数と みなして，採卵率を求めた。比較のためこれとは別に， 交配後 5 日目の午前中にと殺した雌の子宮を摘出し, 子 宮灌流法によって卵子を採取し, 同様に採卵率を求め た。

既述の方法で交配後 5 日目のラットの子宮内卵子の非 外科的採取を試みた結果，Table 1 に示すように, 30 匹の雌すべてから総数 119 個（平均 4.0 個）の卵子（ほ とんど胚盤胞期胚）の回収に成功し，その採卵率は， $40.7 \%$ であった。この非外科的方法による採卵率は, 摘 出子宮灌流法の採卵率 $(81.0 \%)$ に比べるとまだ非常に 低いものであった。しかし, 過排卵誘起したウシの子宮 内胚の非外科的採取法による採卵率をみても40〜60\%が 現状なので $[1,3 〜 6]$ 本実験のような小型の動物を扱っ ての成績としてはまずまずの出来といえよう。

本実験の採卵結果から，用いた器具の反省をしてみる と, ラッパ状ガラス管の先端をできる限り太くすること が理想ではあるが，外径 $1.4 \mathrm{~mm}$ 以上をこすと挿入時に 頸管を痛めることなどから限度があり, 結局すき間から の液の漏出を防ぎきれなかったこと, また, 灌流液注入 用ピペットの先端を子宮角内に挿入する場合, ガラス製 のために折れる危険性があり，ごく浅くしか入れること ができなかったので子宮角上部の洗滌が不完全であった 
Table 1. Comparison of the recovery rate of uterine embryos by non-surgery and slaughter

\begin{tabular}{lccccc}
\hline Method & $\begin{array}{c}\text { No. of } \\
\text { animals } \\
\text { attempted }\end{array}$ & $\begin{array}{c}\text { Total No. } \\
\text { of } \\
\text { CL* }\end{array}$ & $\begin{array}{c}\text { Total No. } \\
\text { of } \\
\text { embryos } \\
\text { recovered }\end{array}$ & recovery & $\begin{array}{c}\text { Average No. } \\
\text { of embryos } \\
\text { animal }\end{array}$ \\
\hline Non-surgery & 30 & 293 & 119 & 40.7 & 4.0 \\
Slaughter & 25 & 258 & 209 & 81.0 & 8.4 \\
\hline $\begin{array}{l}\text { Embryos were collected in all attempts } \\
* \text { CL counted after slaughter of the donors }\end{array}$
\end{tabular}

\section{ことなどが考えられる。}

したがって，今後，採卵率を向上させるには，安全な 材質のもので子宮内液を完全に回収できる器具を考案す ることが先決であろら。

\section{文献}

[1] Betteridge, K. J. (1977). Embryo Transfer in Farm Animals, pp. 10-19. Canada Department of Agriculture, Ottawa.

[2] Dickmann, Z. (1971). Methods in Mammalian Embryology, pp. 133-145. Daniel, Jr. J. C. (edit), W. H. Freeman and Company, San Francisco.

[3] Elsden, R. P., Hasler, J. F., and Seidel, G. F. Jr. (1976). Theriogenology, 6, 523-532.

[4] Newcomb, R., Christie, W. B., and Rowson, L. E. A. (1978). Vet. Rec., 102, 414-417.
[5] Rowe, R. F., Del Campo, M. R., Eilts, C. L., French, L. R., Winch, R. P., and Ginther, O. J. (1976). Theriogenology, 6, 471-483.

［6］杉江 佶・相馬 正・福光 進・大槻清彦 (1972). 畜試 研報, 25, 27-33.

［7] 武田哲男 - 山本謙二 ・田辺泰博 - 堤 義雄 (1977). 北大 農邦文紀要, 10, 231-240.

[8] Takeda, T., Tsutsumi, Y., Tanabe, Y., and Yamamoto, K. (1977). Fertil. Steril., 28, 759-761.

[9] Takeda, T., Suzuki, H., Matsui, S., Terami, Y., and Tsutsumi, Y. (1978). Japan. J. Anim. Reprod., 24, 184-191.

[10] Tsutsumi, Y., Takeda, T., Yamamoto, K., and Tanabe, Y. (1976). J. Reprod. Fert., 48, 393-395.

[11] Tsutsumi, Y., Takeda, T., Ida, M., and Hara, S. (1978). J. Facul. Agr., Hokkaido Univ., 58, 557-574.

[12］湯原正高 - 内海恭三・野上与志郎 - 坂本寿文 - 奥山 博 (1973). 岡大農学報, 42, 27-32. 